\title{
The Japanese Views of Death and Life and Human Remains
}

\section{Aki Kanayama*}

Department of Forensic Odontology and Forensic Anthropology, Tokyo Dental College, Japan

*Corresponding author: Aki Kanayama, Research Student, Department of Forensic Odontology and Forensic Anthropology, Tokyo Dental College, Japan, Tel: 0473220151; E-mail: aki.kanayama07@gmail.com

Received date: December 18, 2017; Accepted date: December 26, 2017; Published date: December 29, 2017

Copyright: (c) 2017 Kanayama A. This is an open-access article distributed under the terms of the Creative Commons Attribution License, which permits unrestricted use, distribution, and reproduction in any medium, provided the original author and source are credited.

\begin{abstract}
In general, views of death and life or human remains differ depending on religions, cultures or countries. The Japanese perception of life and death is also unique. Hence, if Japanese are involved in disasters or accidents, and lose their lives abroad, these differences in views might lead to diplomatic issues or international conflicts. There were some cases that caused international problems in the past. For example, Ehime-maru incident which occurred offshore Hawaii in 2001, and Christchurch earthquake in New Zealand in 2011. The aim of this report is to make the Japanese views and thoughts on death and life, and human remains known worldwide and understood internationally.
\end{abstract}

Keywords: Japanese people; Death and life; Human remains

\section{Introduction}

Attitude towards death, human remains, and entombing vary depending on religions, cultures and countries. The Japanese views are also particular and uncommon for other countries. Therefore, if Japanese lose their lives abroad after being involved in disasters or accidents, diplomatic issues might arise due to the cultural differences or misunderstandings.

In order to avoid these unnecessary problems and conflicts in a chaos, I tried to outline Japanese views on this particular topic in a plain way and classified them into five categories.

\section{Making corpses have humanity}

Even after victims are dead, bereaved families see their bodies as living persons. Thus, they have a strong feeling of rejection to autopsies as they do not want to hurt their bodies anymore.

Therefore, getting approvals from bereaved families in the case of consented autopsies is still not easily achievable in many cases in Japan [1].

\section{Treating corpses in the same way as living persons}

Bereaved families claim the bodies of the deceased in order to bring them home as early as possible since they think it is cold, hot or lonely for victims to stay in morgues.

There were several cases of misplacing victims in the past due to this notion. In The Great East Japan Earthquake in 2011, there were nine misplacing cases as a result of bereaved families' demands for handing over victims' bodies in the initial stages (Figure: 1-3).

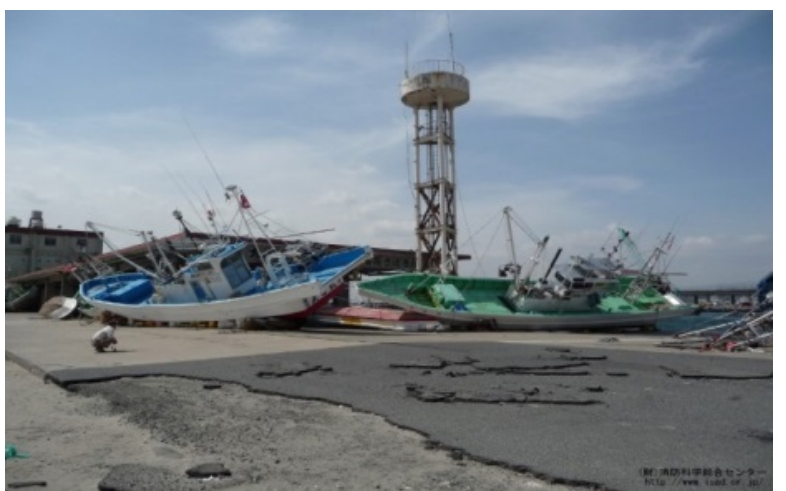

Figure 1: Otsu Harbor in Ibaragi after being struck by the Tsunami at The Great East Japan Earthquake in 2011.

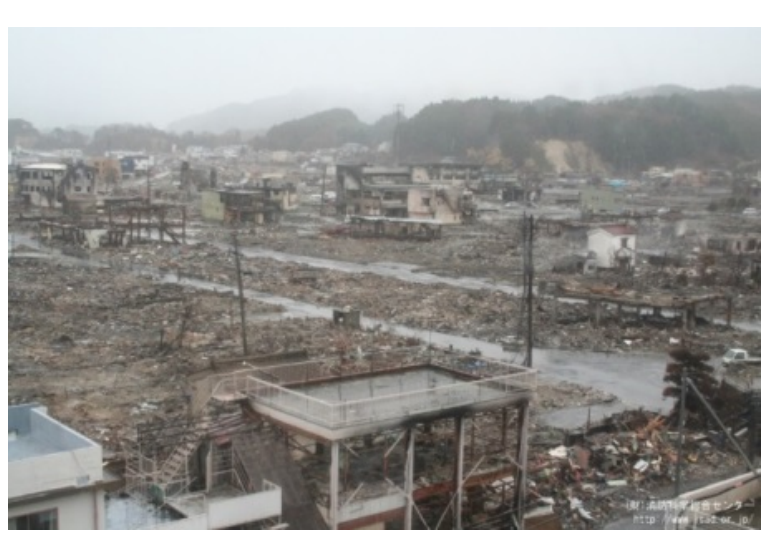

Figure 2: The city center in Yamada area, Iwate at The Great East Japan Earthquake in 2011. 


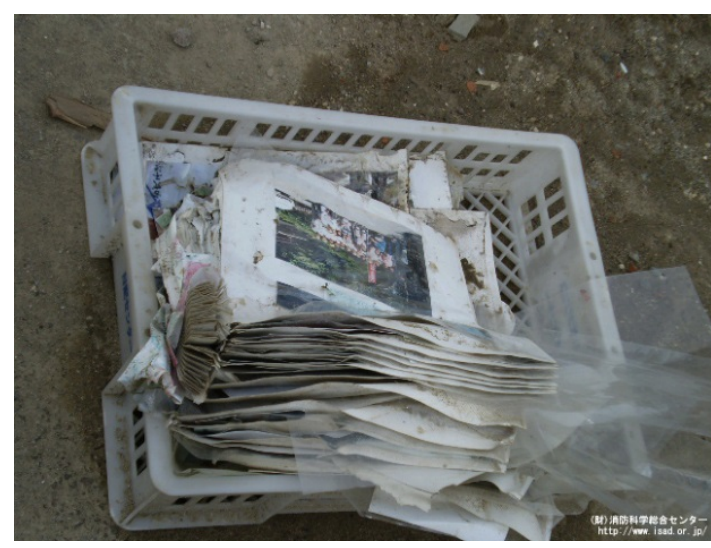

Figure 3: Photo albums found in Miyagi at The Great East Japan earthquake in 2011.

Overseas, in some cases during autopsies, lower jaws of human remains are intersected in order to be examined more precisely if victims' mouths cannot be widely opened. However, this is surely something that Japanese bereaved families do not approve of as they see the victims' bodies as if they are still alive.

\section{Believing in the existence of the life after death}

Generally speaking, Japanese believe in the existence of the life after death. Most of them believe there is another life after death. It is natural for bereaved families to think the deceased will have a tough time in another world if they lost their body parts such as limbs or eyes. They think if the deceased is missing their dominant hands, they cannot eat food there.

Thus, the grieving families desperately try to find their body parts. Because of these Japanese particular thoughts or a sort of religious beliefs backed by Buddhism and Shintoism, the number of organ donors has not increased even though medical facilities are fully equipped and there are domestic demands of organ transplantations [2].

\section{Human remains are essential}

The holistic theory is fundamentally accepted in Japan. For Japanese, human remains do not merely mean corpses without souls, but much more than that.

They believe that cremating bodies and consoling souls of the deceased are the last duties of the families. Therefore, retrieving victims' bodies should be prioritized above anything else. Sometimes, the bereaved families ask for unreasonable favors rather than negotiating the compensation.

In Christchurch earthquake in New Zealand 2011, the ICPO (International Criminal Police Organization) method of DVI (Disaster Victim Identification) was employed. It means that in the process of identifying victims, not only physical appearance or traits were relied on. Thus, it took about a week to get the outcomes. The method was used in order to prevent misplacing the victims there. However, some complaints were heard from the Japanese side due to this lengthy process [3].

\section{Not believing in the death of a person until verifying or identifying the human remains}

The bereaved families also try to search for the missing victims by themselves, as they cannot completely entrust authorities or third parties to find their missing family members. The reason for this is because they cannot fully accept their loved ones' death until they make sure of their death visually or physically by themselves.

In JAL (Japan Air Lines) plane crash incident in 1985, 520 passengers aboard were killed in Gunma, Japan. Thousands of grieving families rushed to a gymnasium which was a temporary morgue near the crashed field. The families of the victims desperately walked around in the gym along with the investigators, pathologists, and odontologists, and tried to find their loved ones. They hoped to find something related to the victims even if it was just a part of their bodies. This operation in the gym lasted for more than one month during the middle of sweltering summer without a cooling system [4].

\section{Ehime-maru incident}

There was a case in the past which caused diplomatic problems between Japan and the USA due to the cultural differences regarding the views of death. It is called Ehime-maru incident which occurred offshore Hawaii in 2001. Ehime-maru was a training boat of Fishery high school in Ehime, Japan. 35 crew members were aboard including high school students when their boat was struck by the U.S. Naval submarine, Greeneville. Nine crew members of Ehime-maru lost their lives in this incident. The eight out of nine crew members' remains were found in the sunken boat eight months later after the incident, but one is still missing in the sea [5].

The U.S. Navy was about to finish the search of these missing nine crew members of Ehime-maru three days after the collision. However, the Japanese government strongly demanded that the search be continued. The U.S. side resumed the search for about 10 days additionally. In the USA, if someone was missing in the sea, the search mostly took a few days. Yet, the solid demand from the Japanese side was taken into consideration at that time [6].

Two different views were clearly observed in this incident. For the Japanese side, the most important priority is to retrieve the remains of the victims in the sea. On the other hand, for the U.S. side, the human remains of those who lost their lives in the sea were not retrieved, as it is believed that they are sleeping forever according to their culture and customs.

Nevertheless, The US side valued the Japanese thoughts and opinions, since they were not responsible for the Ehime-maru's incident. The boat Ehime-maru was underway when the giant rapid floating submarine that was emerging suddenly struck it causing the collision [7].

Eventually, the sunken boat was dragged into the shallow water in order to find the nine missing crew members eight months after the incident. The eight victims' remains were found in the boat and retrieved by divers, but one crew member was not found in the end.

The sunken boat was dragged into 35 meters sea depth from 600 meters. It was unprecedented to drag a sunken boat from such a deepsea bottom. There was much discussion about this in the U.S. since this extraordinary search cost almost 88 million USD at that time [5]. It can be said this unexampled search was accomplished as distinct 
Citation: Kanayama A (2017) The Japanese Views of Death and Life and Human Remains. J Forensic Res 8: 404. doi:

Page 3 of 3

cultural views of death and life were well considered and esteemed between these two countries.

\section{Discussion and Conclusion}

In conclusion, the attitude towards death, human remains and entombing obviously vary depending on religions, cultures and countries. Much attention should be paid in case multinational victims are involved in large-scale disasters to avoid unnecessary diplomatic issues and conflicts in a chaos. Therefore, international guidelines on this matter should be discussed and established as quickly as possible.

\section{Acknowledgments}

The author wishes to acknowledge the contribution to Professor Masatsugu Hashimoto of the Tokyo Dental College Department of Forensic Odontology and Forensic Anthropology for sharing his incomparable experience and providing the author with the fundamental background about the Japanese views of human remains and death and life.

\section{References}

1. Kaido T (2007) Unknown cause of death society. Kodansha Ltd., Tokyo, Japan.

2. Ikeguchi GT (2007) Structural analysis the factors pertaining to attitudes toward and consciousness of organ donation: Comparison between Japanese and Americans. J Okayama Medical Association 119: 153-163.

3. Jouji H, Hiroshi O (2001) Report of early medical support of christchurch earthquake in 2011. J Reg Emerg Disaster Med Res 10: 15-22.

4. Suzuki K (1999) Investigation of dead bodies, Kodansha Ltd., Tokyo, Japan

5. Lewis JA Jr, Shiroma CY, Von Guenthner K, Dunn KN (2004) Recovery and identification of the victims of the Ehime Maru/USS Greeneville Collision at sea. J Forensic Sci 49: 539-42.

6. Oshita D (2007) Death for the Japanese. Emergency Care (2007) 20:18-22

7. Terada M (2001) The 'Ehime-Maru' Incident from a different perspective. Institute for Ocean Policy, SOF Ship \& Ocean News Letter Selected 2: $10-11$. 